$12-1-2018$

\title{
Assessment of the Relationship of Stock and Recruitment in the Atlantic Surfclam Spisula solidissima in the Northwestern Atlantic Ocean
}

Jeremy R. Timbs

Eric N. Powell

Roger L. Mann

Virginia Institute of Marine Science

Follow this and additional works at: https://scholarworks.wm.edu/vimsarticles

Part of the Aquaculture and Fisheries Commons, and the Marine Biology Commons

\section{Recommended Citation}

Timbs, Jeremy R.; Powell, Eric N.; and Mann, Roger L., "Assessment of the Relationship of Stock and Recruitment in the Atlantic Surfclam Spisula solidissima in the Northwestern Atlantic Ocean" (2018). VIMS Articles. 1338.

https://scholarworks.wm.edu/vimsarticles/1338 


\title{
ASSESSMENT OF THE RELATIONSHIP OF STOCK AND RECRUITMENT IN THE ATLANTIC SURFCLAM SPISULA SOLIDISSIMA IN THE NORTHWESTERN ATLANTIC OCEAN
}

\author{
JEREMY R. TIMBS, ${ }^{1 *}$ ERIC N. POWELL ${ }^{1}$ AND ROGER MANN ${ }^{2}$ \\ ${ }^{1}$ Gulf Coast Research Laboratory, The University of Southern Mississippi, 703 East Beach Drive, Ocean \\ Springs, MS 39564; ${ }^{2}$ Virginia Institute of Marine Sciences, The College of William and Mary, Rt. 1208 \\ Greate Road, Gloucester Point, VA 23062-1346
}

\begin{abstract}
Atlantic surfclams support a major commercial fishery in the western North Atlantic Ocean with landings consistently between 15,000 and 25,000 metric tons since 1982 . The stock is not and historically has not been overfished nor has overfishing occurred; however, in recent years landings per unit effort have declined. Surfclams are a biomass dominant on the continental shelf and a bellwether of climate change in the northwestern Atlantic. This study investigated the relationship of broodstock and recruitment during a period when Mid-Atlantic warming initiated a shelf-wide shift in the surfclams range. A species distribution function model was used to assess the effective area occupied by surfclams for five study regions (Delmarva, New Jersey, Long Island, Southern New England, and Georges Bank). The effective area occupied by small surfclams was consistently much greater than that for large $(\geq 120 \mathrm{~mm})$ surfclams. Three independent statistical analyses of the stock-recruitment relationship found little evidence of a significant association in any of the five regions, suggesting that factors besides spawning stock biomass (SSB) are primary determinants of recruitment success. Interannual variability in recruitment, in part associated with variations in larval transport and in part associated with spatially different rates of mortality post-settlement, is an important source of uncertainty and warming bottom waters driving surfclams into new habitat may decouple any inherent interaction between recruits and SSB. A recruitment index obtained from a fishery-independent survey across the range of the stock, as a consequence, is unlikely to usefully presage changes in abundance of the fishable stock. The wider distribution of settlers relative to the fishable stock, however, positions the species well to respond to changing bottom water temperatures as Mid-Atlantic warming continues.
\end{abstract}

KEY WORDS: ocean warming, clam fishery, effective area, biomass dominant, spawning stock biomass, recruitment index, Spisula solidissima

\section{INTRODUCTION}

Atlantic surfclams Spisula solidissima support a major commercial fishery in the western North Atlantic Ocean. Around 20,000 metric tons of surfclam meat were landed in 2015 with landings consistently between 15,000 and 25,000 metric tons since 1982 (NEFSC 2017). Recent stock assessments show that recruitment has been low in the southern portion of the surfclams range post year 2,000, whereas Zhang et al. (2015) provide some support to suggest that larval supply is not a limiting factor. According to recent stock assessments (NEFSC 2017), the surfclam is not overfished and overfishing is not occurring; however, landings per unit effort have declined. That being said, landings per unit effort is not necessarily a good measure of fishable biomass for patchily distributed sedentary species such as the Atlantic surfclam, as dense patches are targeted preferentially by the fishery (Powell et al. 2015, 2016, Kuykendall et al. 2017).

An important population dynamics relationship for the assessment of fisheries is the relationship between spawning stock biomass (SSB) and recruitment. Many examples are available of fisheries being overfished to the point where recruitment declines and the stock collapses (Cushing 1971, Hilborn \& Walters 1992, Myers et al. 1996), shellfish are no exception (Jackson et al. 2001, Kraeuter et al. 2008, Tettelbach et al. 2013). For sessile and sedentary species, the potential of Allee effects

*Corresponding author. E-mail: jeremy.timbs@usm.edu DOI: $10.2983 / 035.037 .0507$ cannot be discounted (Shepherd et al. 1998, Kraeuter et al. 2005, Tettelbach et al. 2013), although behavioral adaptations may mitigate the probability (Buroker 1983, Kraeuter et al. 2008, Ambrogio \& Pechenik 2009, Tettelbach et al. 2017). An example is the hard clam Mercenaria mercenaria, where unsustainable fishing mortality led to recruitment overfishing in both North Carolina and New York (Peterson 2002, Kraeuter et al. 2005).

A relationship between recruitment and SSB is consequential in determining the reference points supporting maximum sustainable yield (Brooks 2013, Mangel et al. 2013, Powell et al. 2018). One difficulty when dealing with bivalves is the rarity of a clear relationship between SSB and recruitment (Hancock 1973, Peterson \& Summerson 1992, Kraeuter et al. 2005, Powell et al. 2009), and the relationship is inherently important in understanding the population dynamics of a species (McGarvey et al. 1993, Harris et al. 1998, Honkoop et al. 1998). A crucial reason for limited evidence of a broodstock-recruitment relationship in bivalves is the importance of recruit survival determining the degree and spatial distribution of recruitment (Powell et al. 1984, Guillou \& Tartu 1994, Ólafsson et al. 1994, Hunt et al. 2003). Not infrequently, recruitment occurs in locations inimical to growth to adulthood (Wells \& Gray 1960, Morse \& Hunt 2013, Fuentes-Santos \& Labarta 2015).

Surfclams could follow one of two life history strategies. The first scenario is that surfclams are $k$-selected (Pianka 1970, Stearns 1976); such species have an expected relationship between SSB and recruitment (Adams 1980, Goodwin et al. 2006). Surfclams have a long life span (Jones et al. 1978, Munroe et al. 
2016) consistent with the $k$-selected end of the $\mathrm{r} / \mathrm{K}$ continuum. The second scenario is that surfclams are bet-hedgers (Pianka 1970, Stearns 1976). These are species with long life spans that, nonetheless, produce large numbers of young yearly while generating substantive recruitment events much less frequently due to inimical conditions during the planktonic or juvenile life span. Bet-hedging lowers the variance in fitness between good and poor environmental conditions to maximize long-term fitness (Olofsson et al. 2009). This provides the bet-hedger the opportunity to maintain its fitness in an unpredictable environment. An important outcome is the potential for decoupling of SSB from recruitment (Hornbach et al. 1981). One consequence of this decoupling is that predicting one variable based on the other becomes increasingly difficult. Surfclams produce large numbers of offspring, few of which survive to maturity. Surfclams also suffer high post-settlement mortality (MacKenzie et al. 1985, Quijón et al. 2007). These are characteristics of the bet-hedging mode of life.

Potentially, confounding any relationship between SSB and recruitment is the fact that juvenile surfclam distribution is significantly different from the distribution of market-size clams, suggesting that many recruits fail to survive in suboptimal habitat (Timbs et al. in review). The area of interest for this study is the Mid-Atlantic Bight (MAB) and Georges Bank (GBK). The MAB with GBK have historically been subdivided into five regions [Delmarva (DMV), New Jersey (NJ), Long Island (LI), Southern New England (SNE), and GBK] for surfclam stock assessment purposes. Surfclam larvae remain in the plankton for 20-30 days (Goldberg 1989, Cargnelli et al. 1999, Zhang et al. 2015), much too short a time for the entirety of the Mid-Atlantic broodstock to participate in recruitment in all regions, and this possibility is further minimized by prevailing currents. Surfclam larvae are carried by southwesterly flowing currents in the MAB, with the exception of GBK; thus, recruitment in any region may result from spawning activity therein or to the north and east (Zhang et al. 2015, 2016). One extreme consequence is larval drifting beyond the southern range boundary, these larvae being lost to the population. The dynamics of recruitment, then, may preclude development of a useful recruitment index as an indicator of future adult biomass and distribution.

Determining how SSB and recruitment are related are additionally important because of the sensitivity of the Atlantic surfclam to climate change. Surfclams have a narrow upper temperature range between optimal and lethal, which makes this species a bellwether species for climate change (Hofmann et al. 2018). In particular, the surfclam stock has been shifting its range north and offshore over the course of many decades, with a distinct acceleration beginning circa 2000. The response of surfclams to warming bottom water temperatures has received considerable attention because it is both a biomass dominant on the inner continental shelf of the northeastern U.S. coast and supports an important fishery (Kim \& Powell 2004, Weinberg 2005, Weinberg et al. 2005, Narváez et al. 2015, Munroe et al. 2016).

The objective of this study was to examine the relationship between SSB and recruitment to determine the following: (1) whether a quantitative relationship between SSB and recruitment can be identified using $30+$ years of comprehensive survey data, (2) whether the relationship between SSB and recruitment has changed over the past $30+$ years during a period of climate change by incorporating larval dispersal model projections, and (3) if the effective area of recruits is consistent with the adult distribution.

\section{MATERIALS AND METHODS}

Data for the Atlantic surfclam used in this study were collected by the National Marine Fisheries Service Northeast Fisheries Science Center stock assessment surveys, which took place every 2-3 y beginning in 1982 and continuing to 2011 (all references to a survey hereafter refers to the Northeast Fisheries Science Center stock assessment survey). Surveys subsequent to 2011 used a larger dredge and different survey vessel and, consequently, have been excluded to eliminate the uncertainty imposed by conflation of data from gears of differential efficiency and selectivity. Figure 1 shows the location of each tow across the entirety of the surfclam survey domain from 1982 to 2011 and the subdivisions of the region (DMV, NJ, LI, SNE, and GBK) historically used for assessment of the status of the stock (NEFSC 2007) and used by Zhang et al. $(2015,2016)$ to examine larval transport dynamics throughout the MAB.

Surfclams are patchily distributed throughout the MAB and this distribution pattern has changed over time. Therefore, the estimated areal coverage of surfclams used for calculation of $\mathrm{SSB}$ and recruits was derived from a species distribution function (SDF) model developed by Thorson et al. (2016). The effective area is estimated as total $\mathrm{km}^{2}$ occupied by surfclams in each region over time. This model uses survey data to estimate model parameters for expected densities within a spatial domain for each given location and employs spatial autocorrelation to predict changes in effective area over time (Thorson et al. 2016). Timbs et al. (in review) provide additional details.

The Atlantic surfclam survey has occurred every 2-3 y. A three-parameter von Bertalanffy growth equation was used to predict the age at length of a surfclam in a given survey year:

$$
\text { shell length }=L_{\infty}\left(1-\mathrm{e}^{-k\left(t-t_{0}\right)}\right),
$$

where $L_{\infty}$ is the asymptotic shell length, $k$ is the Brody growth constant, $t$ is time, and $t_{0}$ is the age at which the organism would have a size of zero. The parameters needed for this calculation were obtained from NEFSC (2013). Because the dredge used for the survey is size selective, surfclams smaller than $60 \mathrm{~mm}$ were excluded from this analysis. Recruits were defined as animals of a given age that would have been spawned the year of the previous survey. Therefore, the number of recruits in a given year was calculated from the number of clams at a particular shell length observed in the subsequent survey based on the age at length obtained from the von Bertalanffy relationship:

$$
R=A_{\mathrm{R}} *\left(\frac{\sum\left(c_{i} / t_{i}\right)}{n}\right) \div \mathrm{e}^{-m \tau}
$$

where $R$ is the number of recruits across the total area, $A_{\mathrm{R}}$ is the total area $\left(\mathrm{km}^{2}\right)$ occupied by the recruits estimated by the SDF model, $c_{i}$ is the number of surfclams caught for the $i$ th tow, $t_{i}$ is the swept area $\left(\mathrm{km}^{2}\right)$ for the $i$ th tow, and $n$ is the total number of tows. This total number of recruits was then increased by backcalculating mortality $(\mathrm{m})$ at a constant rate of 0.15 over the elapsed time $\tau$ between surveys to account for any loss in recruits due to natural mortality. Smaller clams very likely have a 


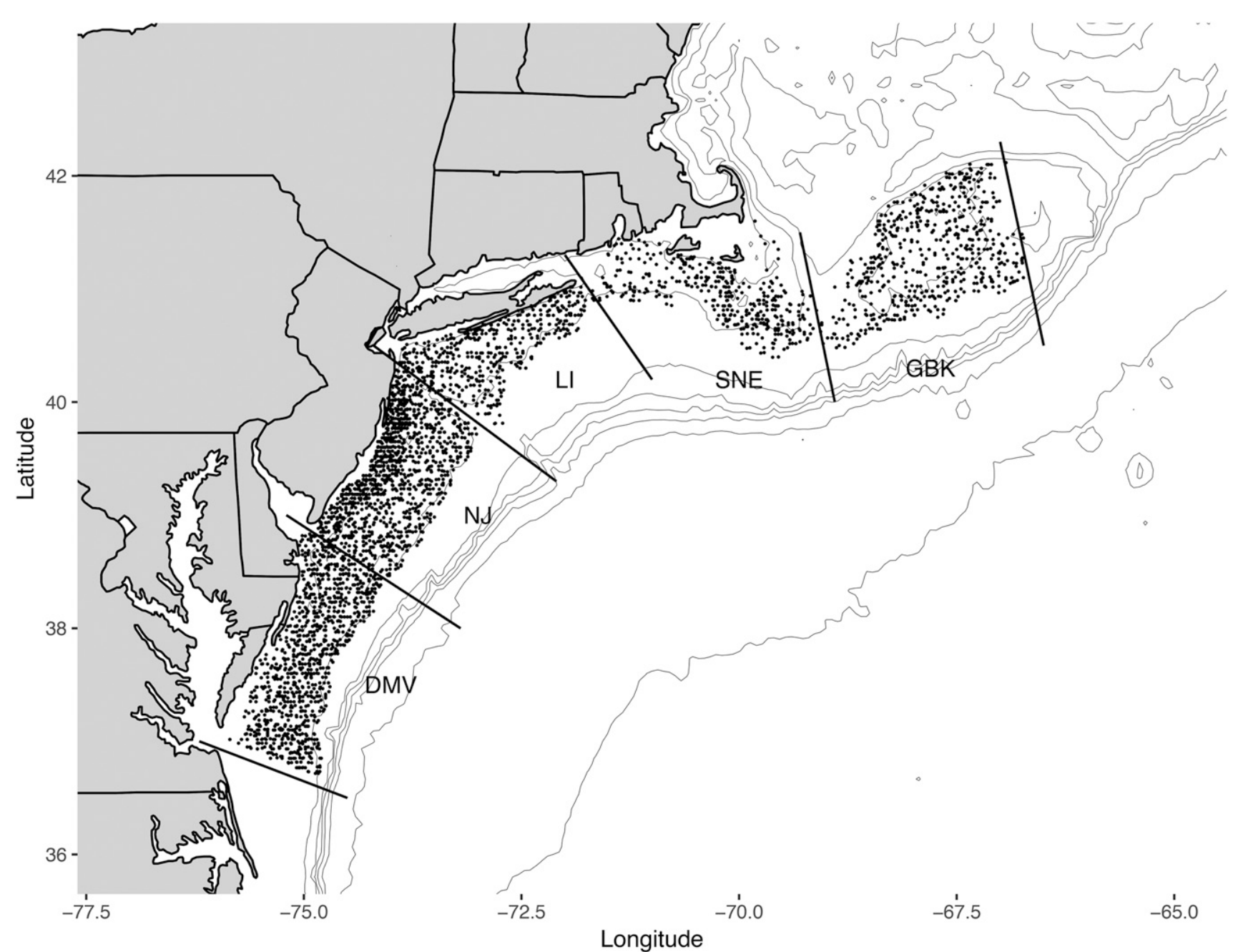

Figure 1. Tow locations for the Atlantic surfclam stock assessment survey from 1982 to 2011. Solid lines delineate the regions of interest (DMV, NJ, LI, SNE, and GBK).

higher mortality rate than larger clams. Consequently, this back-calculation can be expected to yield an underestimate. No information on size-dependent trends in mortality presently exists; thus, the constant mortality assumption used in the surfclam assessment was adopted for this analysis (NEFSC 2017; see also Weinberg 1999).

Spawning stock biomass $(\mathrm{kg})$ was calculated using:

$$
\mathrm{SSB}=A_{\mathrm{SSB}}\left(\frac{\sum\left(w_{i} / t_{i}\right)}{n}\right),
$$

where $A_{\mathrm{SSB}}$ is the total estimated area $\left(\mathrm{km}^{2}\right)$ occupied by the spawning stock from the SDF model, $w_{i}$ is the total summed weight $(\mathrm{kg})$ of the surfclams for the $i$ th tow, $t_{i}$ is the swept area $\left(\mathrm{km}^{2}\right)$ for the $i$ th tow, and $n$ is the total number of tows. The effective area $\left(A_{\mathrm{R}}\right)$ from the SDF model for the recruits was estimated using the data from the clam sizes predicted by the von Bertalanffy relationship to be the size range reached by recruits from a subsequent survey to a given survey (e.g., 64-80 $\mathrm{mm}$ shell length), whereas the effective area used for the SSB calculations was estimated using the data from all surfclams greater than equal to $60 \mathrm{~mm}$ shell length for a given survey. Chintala et al. (2001) showed that surfclams mature at a size below $60 \mathrm{~mm}$, but these clams are not efficiently caught by the survey dredge; hence, SSB is slightly underestimated by their exclusion. Not all strata were sampled in every survey leaving "holes" in the SSB calculation. These "holes" were filled by averaging the number of tows from the same stratum in the previous and/or next survey (NEFSC 2013).

Zhang et al. (2015) showed that larvae potentially recruiting to a region were derived from that region and usually the adjacent region to the northeast. Zhang et al. (2015) used an individual-based larval model that included both growth and behavioral components coupled to the Regional Ocean Modeling System, a free-surface, terrain-following, primitive equations ocean model widely applied by the scientific community for various applications in both deep ocean and coastal settings (Haidvogel et al. 2000, Budgell 2005, Warner et al. 2005, Powell et al. 2008). The coupled larval hydrodynamic model was used to derive larval trajectories from release points in each region throughout the surfclam April-October spawning season. These connectivity data permitted allocation of a portion of the potential recruits from an upstream region into the regions 
downstream. The estimated SSB from each region was allocated into portions representing the percentage of said SSB responsible for larvae released into a downstream region or remaining in the region of origin (Table 1) based on a larval connectivity matrix provided by Zhang et al. (2015; see Zhang, Fig. 8B). The allocated portion of SSB was then apportioned into the percentage of larvae that settled in the downstream region or region of origin (Table 1).

Spearman correlations were used to determine if any relationship existed between observed recruits in a given region and allocated SSB as defined by the Zhang et al. (2015) connectivity matrix. A Ricker SSB and recruitment model was fitted to the data. The Ricker model assumes that recruitment decreases relative to spawning stock at high spawning stock abundance (overcompensation), as might be the case in bivalves where competition for food may reduce fecundity disproportionately at high SSB:

$$
R=\alpha S \mathrm{e}^{-\beta S},
$$

where $R$ is the recruits, $S$ is the SSB, $\alpha$ is the recruits per spawners at low stock sizes, and $\beta$ is the shape of the curve (DeAlteris 2000). The parameters $\alpha$ and $\beta$ were estimated using a nonlinear model in $R$ (programming language) to best fit the data.

A potential relationship between SSB and recruitment was further investigated using quadrant plots defined by the medians of SSB and recruitment. Figure 2 presents the four quadrants defined as: (1) low recruit/low SSB; (2) high recruit/ low SSB; (3) high recruit/high SSB; and (4) low recruit/high SSB (Rothschild \& Mullen 1985). Consecutive survey year transitions were used to derive a transition matrix for calculation of mean first passage times following Redner (2001; see also Rothschild et al. 2005, Rothschild \& Mullen 1985). The mean first passage times are a measure of the number of years likely to elapse before the population with the $x$ - $y$ relationship characteristic for any one quadrant is described by the relationship characteristic of the same quadrant or obtains the relationship characteristic of one of the three other quadrants (Powell et al. 2009).

\section{RESULTS}

\section{Area Analysis}

The SDF model estimated effective areas occupied by the recruits and the larger surfclams for each region. In all regions,

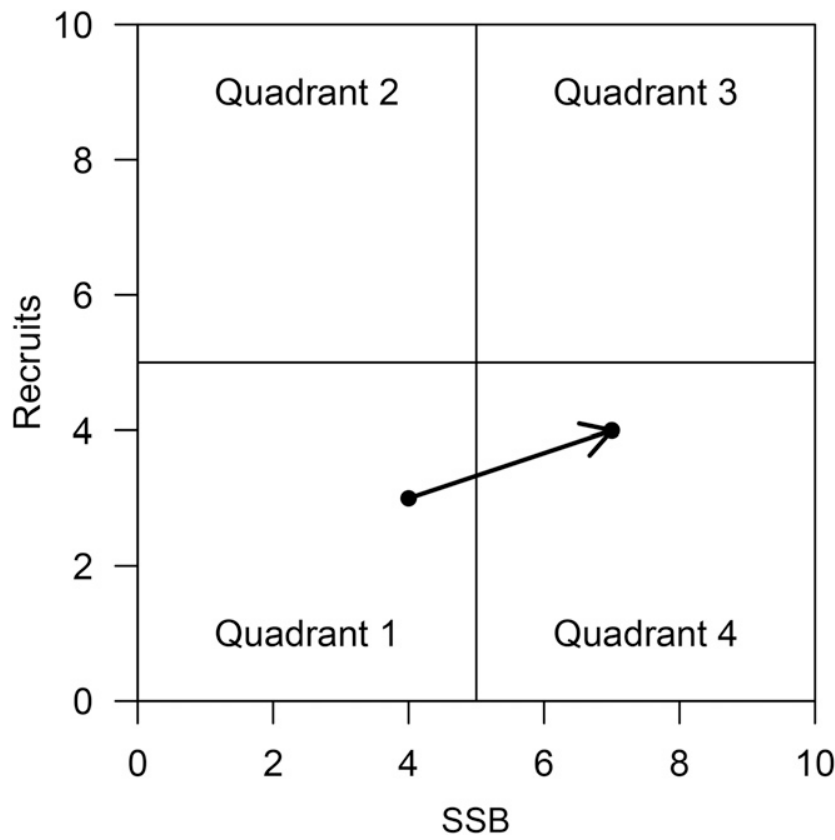

Figure 2. The four quadrants are defined with respect to the medians of SSB (kg) and recruits as follows: (1) low recruit/low SSB (kg); (2) high recruit/low SSB (kg); (3) high recruit/high SSB (kg); and (4) low recruit/ high SSB (kg). The arrow represents an example transition between quadrants from one to four.

the recruits covered a greater area than the larger surfclams. The effective area for both the recruits and larger surfclams in the DMV region fluctuated over time without a noticeable increase or decrease (Fig. 3). This is consistent with the offshore shift in range in this region since circa 2000, which has debited the inshore range while expanding the offshore range. The effective area ranged between $8.1 \times 10^{3}$ and $2.2 \times 10^{4} \mathrm{~km}^{2}$ for the recruits, whereas the effective area for the larger surfclams ranged between $4.9 \times 10^{3}$ and $8.1 \times 10^{3} \mathrm{~km}^{2}$ (Table 2). In DMV, the effective area, on average, was $55 \%$ less for the larger surfclams compared with the recruits. The effective area for both the recruits and larger surfclams in the $\mathrm{NJ}$ region increased over time from the 1980s to the 2000s (Fig. 4). This is consistent with the expansion of the population offshore since circa 2000 (Weinberg et al. 2005), whereas the recession of the inshore boundary has impacted primarily state waters (Hofmann et al.

TABLE 1.

The connectivity data estimated allocation percentages for the DMV, NJ, LI, and SNE regions and on GBK.

\begin{tabular}{|c|c|c|c|c|c|c|c|c|c|c|}
\hline \multirow[b]{2}{*}{ Region } & \multicolumn{2}{|c|}{ DMV } & \multicolumn{2}{|c|}{ NJ } & \multicolumn{2}{|c|}{ LI } & \multicolumn{2}{|c|}{ SNE } & \multicolumn{2}{|c|}{ GBK } \\
\hline & $\mathbf{R}$ & $\mathbf{S}$ & $\mathbf{R}$ & $\mathrm{S}$ & $\mathbf{R}$ & $\mathbf{S}$ & $\mathbf{R}$ & $\mathbf{S}$ & $\mathbf{R}$ & $\mathbf{S}$ \\
\hline Delmarva & 0.3218 & 0.3138 & - & - & - & - & - & - & - & - \\
\hline New Jersey & 0.4698 & 0.4698 & 0.4581 & 0.4702 & - & - & - & - & - & - \\
\hline Long Island & 0.0625 & 0.0646 & 0.6607 & 0.5298 & 0.2768 & 0.9894 & - & - & - & - \\
\hline Southern New England & - & - & - & - & 0.3333 & 0.0106 & 0.6667 & 1.0000 & - & - \\
\hline Georges Bank & - & - & - & - & - & - & - & - & 1.0000 & 1.0000 \\
\hline
\end{tabular}

The estimated SSB $(\mathrm{kg})$ from each region was allocated into portions representing the percentage of said SSB $(\mathrm{kg})$ responsible for larvae released $(R)$ into a downstream region or remaining in the origin region based on the larval connectivity matrix (see Zhang et al. 2015, Fig. 8B). The allocated portion of SSB $(\mathrm{kg})$ was then portioned into the percentage of larvae that settled $(S)$ in the downstream region or origin region. 

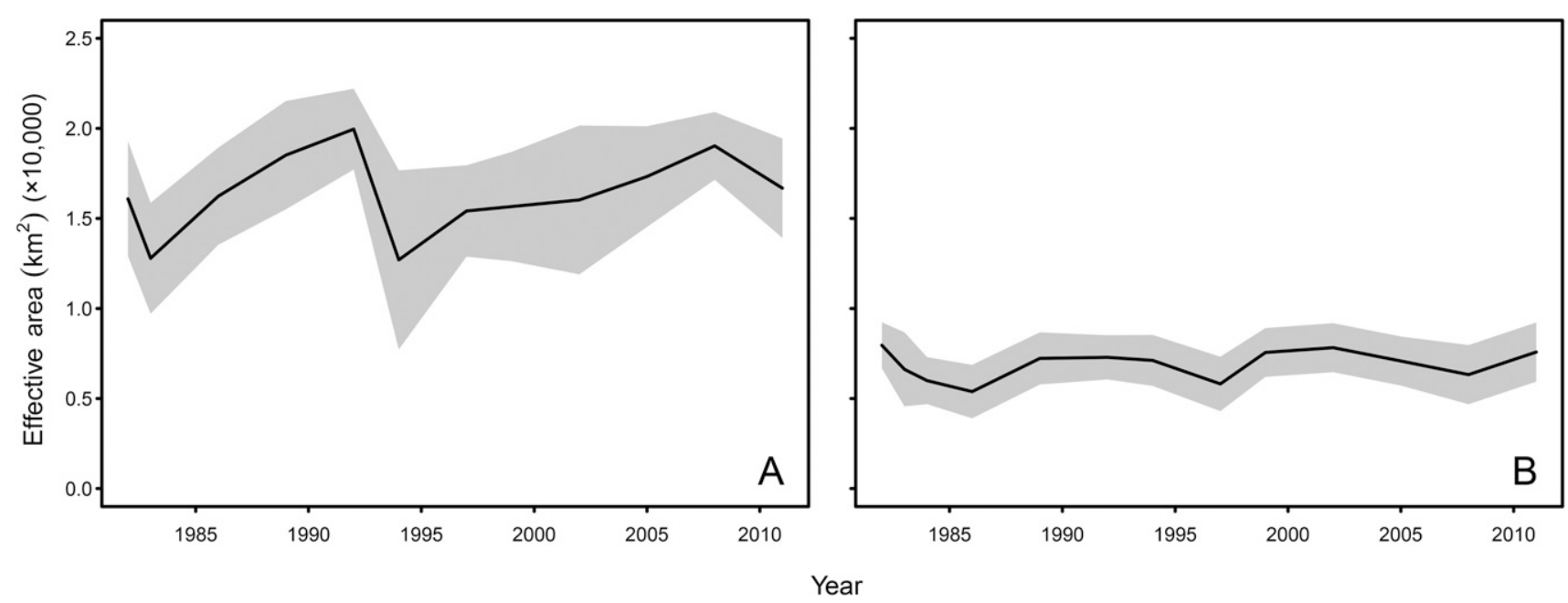

Figure 3. Estimated effective area $\left(\mathrm{km}^{2}\right)$ for (A) recruits and (B) larger surfclams in the DMV region. Both areas fluctuated slightly over time with a $55 \%$ reduction in area from the recruits to the large surfclams. The black line is the maximum likelihood estimate and the grey shaded area is $\pm 1 \mathrm{SE}$.

2018) not considered in this analysis. The effective area for the recruits in the $\mathrm{NJ}$ region fluctuated over time ranging from $7.3 \times 10^{3}$ to $1.5 \times 10^{4} \mathrm{~km}^{2}$ and the effective area for the large surfclams ranged from $5.4 \times 10^{3}$ to $1.1 \times 10^{4} \mathrm{~km}^{2}$ with an average reduction of $21.5 \%$ in the effective area from the recruits to the large surfclams (Table 2). The effective area for the recruits in the LI region fluctuated over time, whereas the effective area for the large surfclams remained constant, with a reduction of $53.1 \%$ in area from the recruits to the large clams (Fig. 5). An offshore range expansion noted in the most recent surveys (NEFSC 2017) is not recorded in the dataset used in this analysis because the most recent years were excluded because of a change in survey gear. In the LI region, the effective area for the recruits ranged from $4.9 \times 10^{3}$ to $9.0 \times 10^{3} \mathrm{~km}^{2}$, whereas the effective area for the large surfclams ranged from $3.0 \times 10^{3}$ to $3.6 \times 10^{3} \mathrm{~km}^{2}$ (Table 2). The effective area in the SNE region for the recruits was much higher with some fluctuations over time than for the larger surfclams for which the effective area remained relatively constant (Fig. 6). The effective area for the recruits and larger surfclams ranged from $7.3 \times 10^{3}$ to $1.1 \times 10^{4}$ and $1.8 \times 10^{3}$ to $2.2 \times 10^{3} \mathrm{~km}^{2}$, respectively, in the SNE region (Table 2). The SNE region had a considerably larger reduction in area of $78.6 \%$ than the other regions between the recruits and larger surfclams. In the GBK region, the effective area for the recruits remained relatively constant over time, whereas the effective area for the larger surfclams increased over time with some fluctuations (Fig. 7). This is consistent with an expansion of the area occupied by surfclams on GBK noted by NEFSC (2013, 2017; see also Timbs et al. in review). The effective area for the recruits on GBK ranged from $1.6 \times$ $10^{3}$ to $2.0 \times 10^{4} \mathrm{~km}^{2}$ with the effective area for the larger surfclams ranging from $3.0 \times 10^{3}$ to $9.9 \times 10^{3} \mathrm{~km}^{2}$ (Table 2). A $59.3 \%$ reduction in area was observed from the recruits to the large clams.

\section{Stock-Recruitment}

The recruits and SSB for each survey year are provided in Table 3 and shown in Figures 8 and 9. Based on the Spearman correlation results, the DMV, LI, and SNE regions exhibit no relationship between the recruits and $\mathrm{SSB}$, whereas the $\mathrm{NJ}$ and GBK regions exhibit a weak negative relationship between the recruits and SSB (Fig. 10) which, however, are not significant. Ricker models highlight that no clear relationship exists

TABLE 2.

Estimated effective area $\left(\mathrm{km}^{2}, \times 1,000\right)$ for recruits and larger SSB surfclams in the DMV, NJ, LI, SNE, and GBK regions.

\begin{tabular}{|c|c|c|c|c|c|c|c|c|c|c|c|c|c|c|}
\hline \multirow[b]{2}{*}{ Region } & \multirow[b]{2}{*}{ Size } & \multicolumn{13}{|c|}{ Year } \\
\hline & & 1982 & 1983 & 1984 & 1986 & 1989 & 1992 & 1994 & 1997 & 1999 & 2002 & 2005 & 2008 & 2011 \\
\hline \multirow[t]{2}{*}{ Delmarva } & Recruits & 16.09 & 12.79 & 0.43 & 16.23 & 18.52 & 19.96 & 12.70 & 15.41 & 15.66 & 16.03 & 17.33 & 19.03 & 16.68 \\
\hline & SSB & 7.96 & 6.62 & 5.99 & 5.49 & 7.23 & 7.29 & 7.12 & 5.81 & 7.56 & 7.82 & 7.08 & 6.33 & 7.58 \\
\hline \multirow[t]{2}{*}{ New Jersey } & Recruits & 7.75 & 10.23 & 8.08 & 8.23 & 7.85 & 13.55 & 9.98 & 12.78 & 10.03 & 15.39 & 13.39 & 13.66 & 13.81 \\
\hline & SSB & 5.71 & 6.79 & 6.57 & 8.01 & 7.49 & 8.67 & 8.23 & 9.70 & 11.20 & 10.46 & 10.47 & 11.06 & 9.27 \\
\hline \multirow[t]{2}{*}{ Long Island } & Recruits & 7.37 & 7.37 & 6.63 & 8.57 & 6.98 & 7.79 & 8.88 & 7.65 & 4.75 & 6.49 & 6.77 & 6.59 & 9.35 \\
\hline & SSB & 2.96 & 3.45 & 3.48 & 3.42 & 3.45 & 3.51 & 3.53 & 3.45 & 3.46 & 3.44 & 3.49 & 3.50 & 3.48 \\
\hline \multirow[t]{2}{*}{ Southern New England } & Recruits & 9.91 & 8.28 & 7.91 & 10.50 & 7.61 & 8.13 & 8.82 & 7.83 & 9.78 & 9.42 & 7.90 & 8.48 & 9.81 \\
\hline & SSB & 2.27 & 1.84 & 1.86 & 1.90 & 1.87 & 1.80 & 1.86 & 1.87 & 1.89 & 1.88 & 1.82 & 1.83 & 1.80 \\
\hline \multirow[t]{2}{*}{ Georges Bank } & Recruits & 17.55 & 19.54 & 19.87 & 1.65 & 19.46 & 17.70 & 18.82 & 15.31 & 17.59 & 18.94 & 19.72 & 19.38 & 16.61 \\
\hline & SSB & 4.44 & 7.20 & 7.34 & 6.65 & 3.10 & 7.85 & 5.10 & 6.72 & 8.79 & 9.78 & 8.46 & 6.80 & 8.10 \\
\hline
\end{tabular}



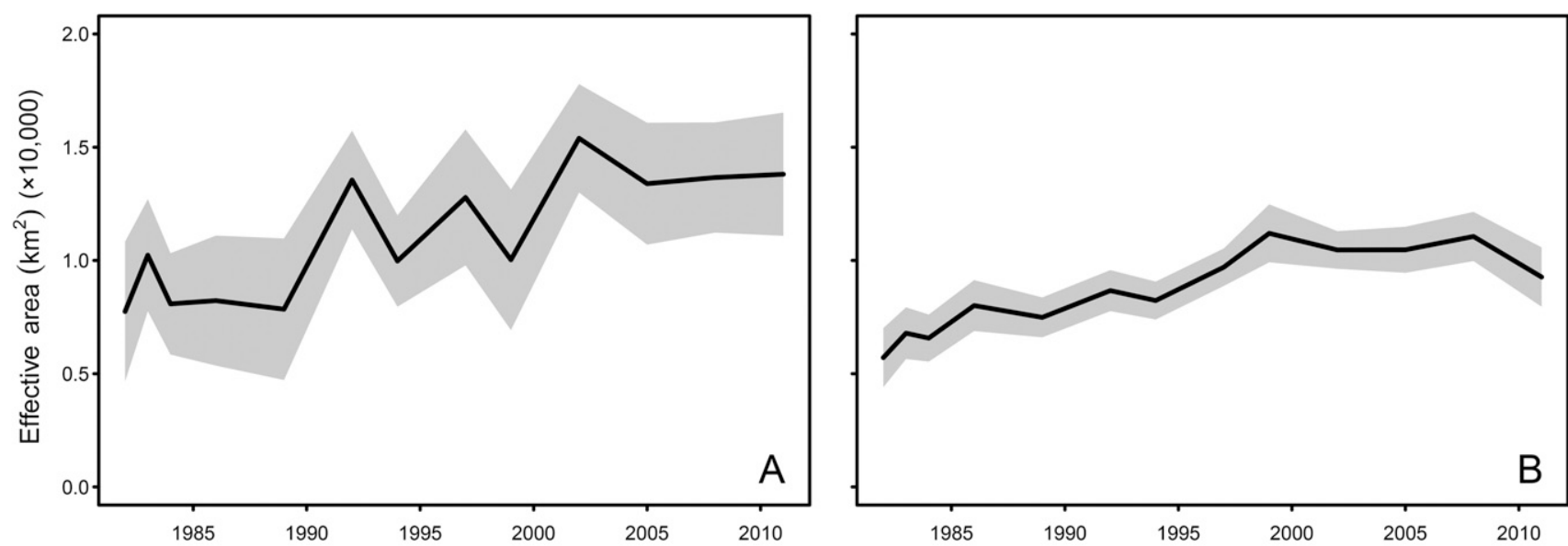

Year

Figure 4. Estimated effective area $\left(\mathrm{km}^{2}\right)$ for (A) recruits and (B) larger surfclams in the $\mathrm{NJ}$ region. Areas for both size classes increased from 1982 to 2011 with a $21.5 \%$ reduction in area from the recruits to the large surfclams. The black line is the maximum likelihood estimate and the grey shaded area is $\pm 1 \mathrm{SE}$.

between the recruits and SSB for any of the study regions (Figs. 8 and 9).

The recruits and SSB for each survey year were allocated to one of four quadrants based on division of each by their respective median (Table 4). Chi-square tests found no significant differences between the number of stock-recruitment points falling into one of the quadrants relative to the others for any of the regions (Table 5). These results indicate the stock and recruitment observations are uniformly distributed among the four quadrants. No relationship exists between the stock and recruits based on this analysis.

The mean first passage times for the DMV region suggested similar transition times between all quadrant pairs (Table 6). In the NJ region, the first passage times estimated that transitioning to quadrant 2 from the other quadrants is more unlikely (Table 6). Quadrant 2 is characterized by high recruitment/low SSB. The first passage times for the LI region point toward a transition to quadrant 1 , low recruitment/low $\mathrm{SSB}$, from the other three quadrants being less likely to occur (Table 6). The SNE mean first passage times suggested the unlikely occurrence of a transition to state 4, low recruitment/ high SSB, from the other quadrants, whereas the GBK region was characterized by the less likely transition to state 3 , high recruitment/high SSB, from the other quadrants (Table 6).

\section{DISCUSSION}

The objective of this study was to determine if a stockrecruitment relationship exists for the Atlantic surfclam. A number of challenges exist in making this determination. Juvenile surfclams may be distributed significantly differently than market-size clams, suggesting that many recruits fail to survive in suboptimal habitat. The area of interest for this study is the MAB and GBK. This area historically has been subdivided into five regions (DMV, NJ, LI, SNE, and GBK) for stock
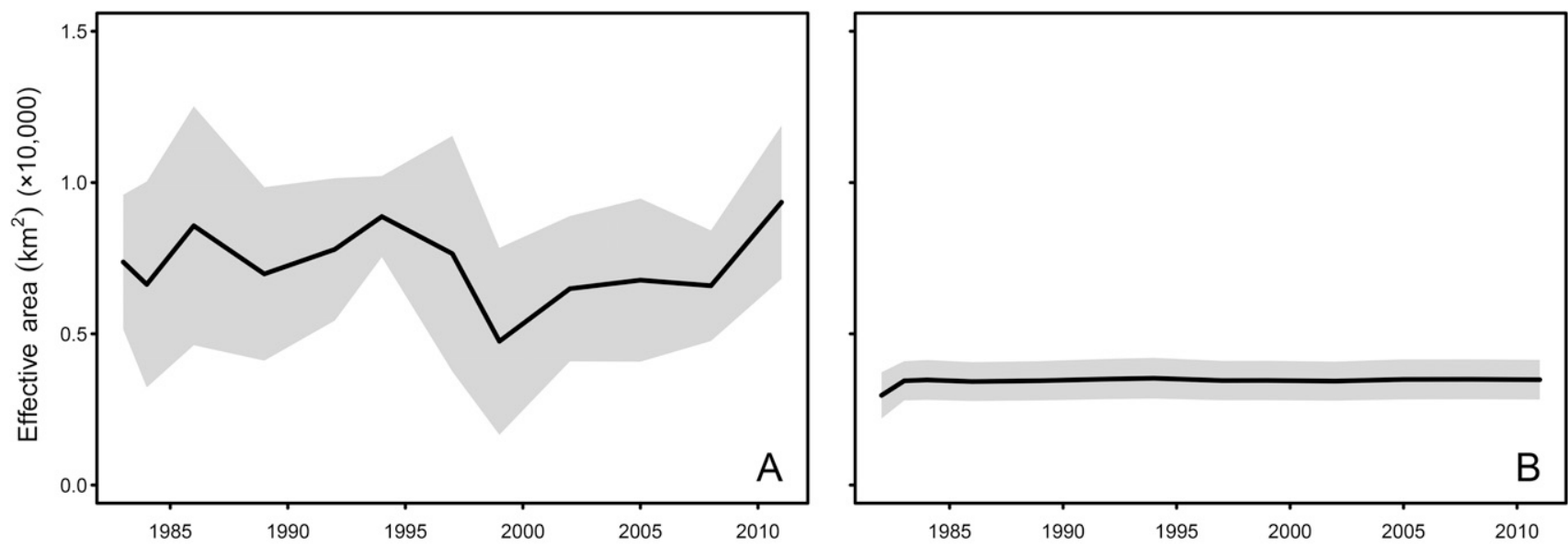

Year

Figure 5. Estimated effective area $\left(\mathrm{km}^{2}\right)$ for (A) recruits and (B) larger surfclams in the LI region. The area for the recruits fluctuated over time with a slight increase, and the area occupied by the large surfclams remained constant over time with a reduction of $53.1 \%$ in area from the recruits to the large clams. The black line is the maximum likelihood estimate and the grey shaded area is $\pm 1 \mathrm{SE}$. 

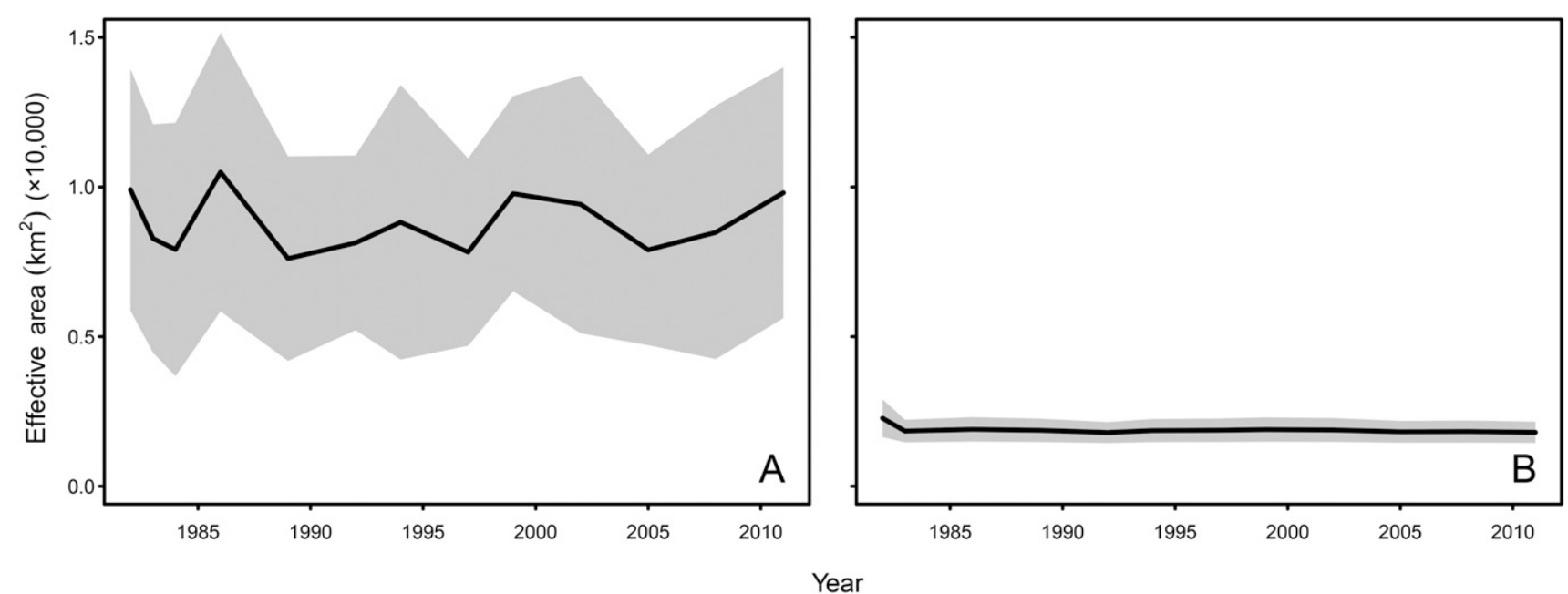

Figure 6. Estimated effective area $\left(\mathrm{km}^{2}\right)$ for $(\mathrm{A})$ recruits and $(B)$ larger surfclams in the SNE region. The area for the recruits fluctuated over time and the larger surfclams remained constant over time. The SNE region had a considerably larger reduction in area of $78.6 \%$ than the other regions between the recruits and larger surfclams. The black line is the maximum likelihood estimate and the grey shaded area is $\pm 1 \mathrm{SE}$.

assessment purposes. Surfclam larvae remain in the plankton for 20-30 days (Goldberg 1989, Cargnelli et al. 1999, Zhang et al. 2015), much too short a time for the entirety of the MidAtlantic broodstock to participate in recruitment in all regions, and this possibility is further minimized by prevailing currents. Surfclam larvae are carried by southwesterly flowing currents in the MAB, with the exception of GBK; thus, recruitment in any region may result from spawning activity therein or to the north and east (Zhang et al. 2015, 2016) and the geographic scale of the contributing spawning stock is highly variable interannually (Zhang et al. 2016). The dynamics of recruitment, then, may complicate development of a useful recruitment index.

During the 1982 to 2011 period, warming of the MidAtlantic bottom waters has occurred, an important result of which has been a shift of the surfclam population offshore and north (Hofmann et al. 2018). Rising temperatures also can be expected to impact recruitment potential as surfclam physiology is strongly temperature dependent (Munroe et al. 2013). This may introduce variability in the relationship between broodstock and recruitment (Rijnsdorp et al. 2009, Dutertre et al. 2010, Shephard et al. 2010). In particular, Perretti et al. (2017) recognized that recruitment success has varied approximately decadally over the 1980 to 2010 period for many northeast continental shelf stocks. The decline in surfclam recruitment noted in the 2000s is consistent with this trend. The triennial survey protocol limits the number of decadal observations and, consequently, identification of regime shifts, as they might influence the relationship between broodstock and recruitment in surfclams, is unlikely. Nonetheless, the time series addressed in this study carries through the late 1990s through early 2000 s period, during which time a regime shift has been described for a number of western Atlantic and Gulf of Mexico species (Lucey \& Nye 2010, Powell 2017) and observed also in the eastern Atlantic (Chaalali et al. 2013, Beukema et al.
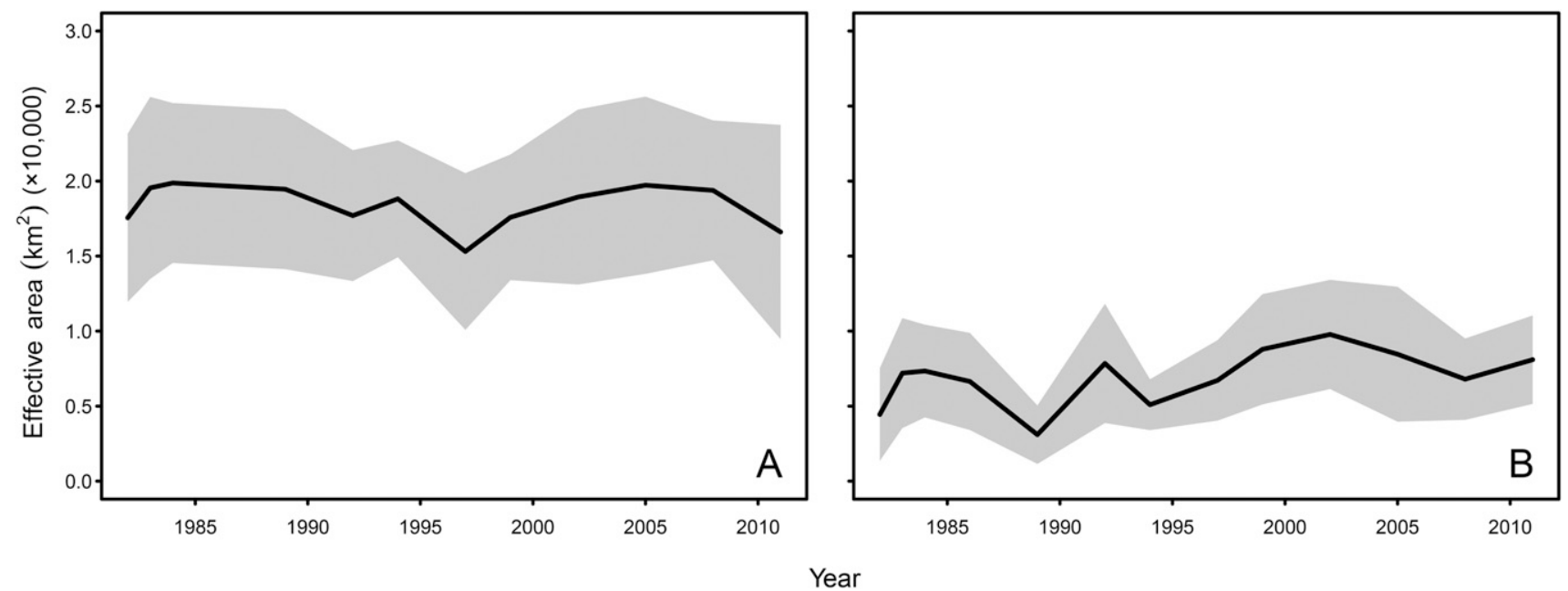

Figure 7. Estimated effective area $\left(\mathrm{km}^{2}\right)$ for (A) recruits and (B) larger surfclams in the GBK region. The area for the recruits slightly fluctuated and the effective area of the larger surfclams fluctuated over time with a slight increase. A $59.3 \%$ reduction in area was observed from the recruits to the large clams. The black line is the maximum likelihood estimate and the grey shaded area is $\pm 1 \mathrm{SE}$. 
TABLE 3.

The number of recruits $(\times 10,000)$ and the SSB $(\mathrm{kg} ; \times 10,000)$ for the DMV, NJ, LI, SNE, and GBK regions.

\begin{tabular}{|c|c|c|c|c|c|c|c|c|c|c|}
\hline \multirow[b]{2}{*}{ Year } & \multicolumn{2}{|c|}{ DMV } & \multicolumn{2}{|c|}{ NJ } & \multicolumn{2}{|c|}{$\mathbf{L I}$} & \multicolumn{2}{|c|}{ SNE } & \multicolumn{2}{|c|}{ GBK } \\
\hline & Recruits & SSB & Recruits & SSB & Recruits & SSB & Recruits & SSB & Recruits & SSB \\
\hline 1982 & 45,637 & 5,439 & 31,521 & 2,981 & 3,865 & 158 & 8,356 & 596 & 139,852 & 347 \\
\hline 1983 & 28,946 & 5,093 & 34,191 & 3,065 & 3,915 & 24 & 5,927 & 1,321 & 443,142 & 60 \\
\hline 1984 & 942 & 5,872 & 27,904 & 3,258 & 4,732 & 133 & 7,352 & 1,210 & 26,730 & 2,333 \\
\hline 1986 & 19,452 & 7,027 & 23,940 & 4,160 & 21,897 & 113 & 16,522 & 542 & 2,890 & 5,983 \\
\hline 1989 & 35,884 & 5,051 & 31,081 & 3,456 & 28,978 & 204 & 18,853 & 576 & 53,621 & 5,976 \\
\hline 1992 & 267,394 & 5,810 & 99,447 & 3,815 & 7,656 & 202 & 3,895 & 468 & 60,886 & 4,641 \\
\hline 1994 & 85,392 & 14,781 & 33,657 & 10,012 & 9,055 & 319 & 21,799 & 170 & 70,739 & 13,137 \\
\hline 1997 & 27,529 & 17,192 & 19,673 & 11,584 & 22,430 & 213 & 11,465 & 1,346 & 37,683 & 13,196 \\
\hline 1999 & 82,215 & 11,074 & 31,323 & 8,150 & 4,579 & 572 & 18,018 & 649 & 42,059 & 6,899 \\
\hline 2002 & 15,839 & 7,841 & 12,715 & 5,274 & 5,264 & 128 & 1,947 & 495 & 29,082 & 3,639 \\
\hline 2005 & 21,705 & 2,728 & 20,147 & 2,534 & 5,342 & 485 & 5,076 & 3 & - & - \\
\hline 2008 & 129,253 & 2,662 & 43,082 & 2,135 & 8,592 & 192 & 3,110 & 368 & 22,059 & 12,543 \\
\hline
\end{tabular}

The Georges Bank region was not sampled in 2005.

2017), and which likely would degrade a long-term relationship between broodstock and recruitment in surfclams.

A series of statistical analyses were performed designed to reveal the relationship between the spawning stock and recruitment over the 1982 to 2011 period, should it exist. Each of these failed to provide unequivocal evidence. These included basic correlation analysis, a by-quadrant analysis with the expectation that quadrants 1 and 3 (Fig. 2, Table 4) would be disproportionately represented, and an analysis of the mean first passage times, with the expectation that certain transitions would be more likely than others (Powell et al. 2009). For the latter, unlikely transitions were observed but they varied between regions, whether this is the provenance of chance within a group of unrelated pairwise relationships or indicative of underlying regional differences cannot be presently determined.

Assuming from these afore-listed analyses that a relationship between recruitment and broodstock does not exist; that is, SSB is relatively inconsequential in determining the temporal dynamics of recruitment, and setting aside the expected stochastic variability that can be anticipated to exist in such a dataset, a number of characteristics of surfclams may foster a limited influence of SSB on recruitment. The discrepancy between the effective area occupied by the recruits and the marketsize ( $\geq 120 \mathrm{~mm}$ ) clams is noteworthy. Based on the SDF model, the estimated effective areas of small surfclams covered a more substantial area than that for market-size clams in all five regions. Post-settlement mortality appears to be an important causative agent in determining the spatial distribution of market-size clams as it certainly is the basis for much of this discrepancy. Thus, surfclams recruit over wide expanses but only in some locations do these individuals survive in large numbers. The consequence of small clams succumbing to natural mortality in a geographically biased manner before entering the fishery decouples the abundance of recruits and that of market-size surfclams.

The clear inference from the differential in effective area between the recruits and the market-size clams is that recruitment occurs in suboptimal habitat lying inshore and offshore of the range boundary established by the larger clams. Results described in Timbs et al. (in review) showed that much of this additional area was located offshore of the range core, likely because mortality of recruits inshore occurred so early in life that the juveniles did not grow large enough to recruit to the survey dredge, as recruitment inshore is well documented (MacKenzie et al. 1985, Chintala \& Grassle 2001, Ma et al. 2006, Quijón et al. 2007). Zhang et al. (2015, 2016) showed that recruitment inshore was a preferential outcome based on the net across-shelf flow on the continental shelf, wherein offshore larval transport occurred less frequently over the spawning season than inshore transport. By inference, then, life spans of the offshore recruits are somewhat longer than that of inshore recruits, allowing some of them to grow large enough to recruit to the survey dredge. What environmental changes limit survival offshore have not been identified; however, large-scale modulations of the cold pool, which occur aperiodically (Sha et al. 2015), may be responsible. The inner wall of the cold pool defines the offshore boundary of the surfclams range core.

Zhang et al. (2016) identified important interannual variability in the potential for recruitment based on interannual variability in the hydrodynamic regime throughout the study domain. Such variability, coupled with post-settlement mortality as a dominant determinant of recruitment success, favors the bet-hedging mode of life. For surfclams, the fact that recruitment cannot be specified from a stock-recruitment relationship is anticipated to result from a bet-hedging strategy in which the variance in fitness imposed by the environment produces unpredictable levels of recruitment in any given year (Stearns 1976, Olofsson et al. 2009, Lovich et al. 2015). In this, surfclams are typical iteroparous bivalves (van der Meer et al. 2003, Beukema et al. 2010, Adkins et al. 2014). Although a Ricker model theoretically should be the bivalve norm, as competition for food when bivalves are at high abundance is well documented and can be expected to limit growth and reproduction (Grizzle \& Lutz 1989, Beukema \& Cadée 1996, Knights 2012), market-size abundance regionally does not seem to reach levels sufficient for that outcome (Munroe et al. 2016). Thus, the Ricker model fails to describe the number of recruits based on a SSB and bet-hedging minimizes the relationship at SSB levels below those engendering competition for food. 


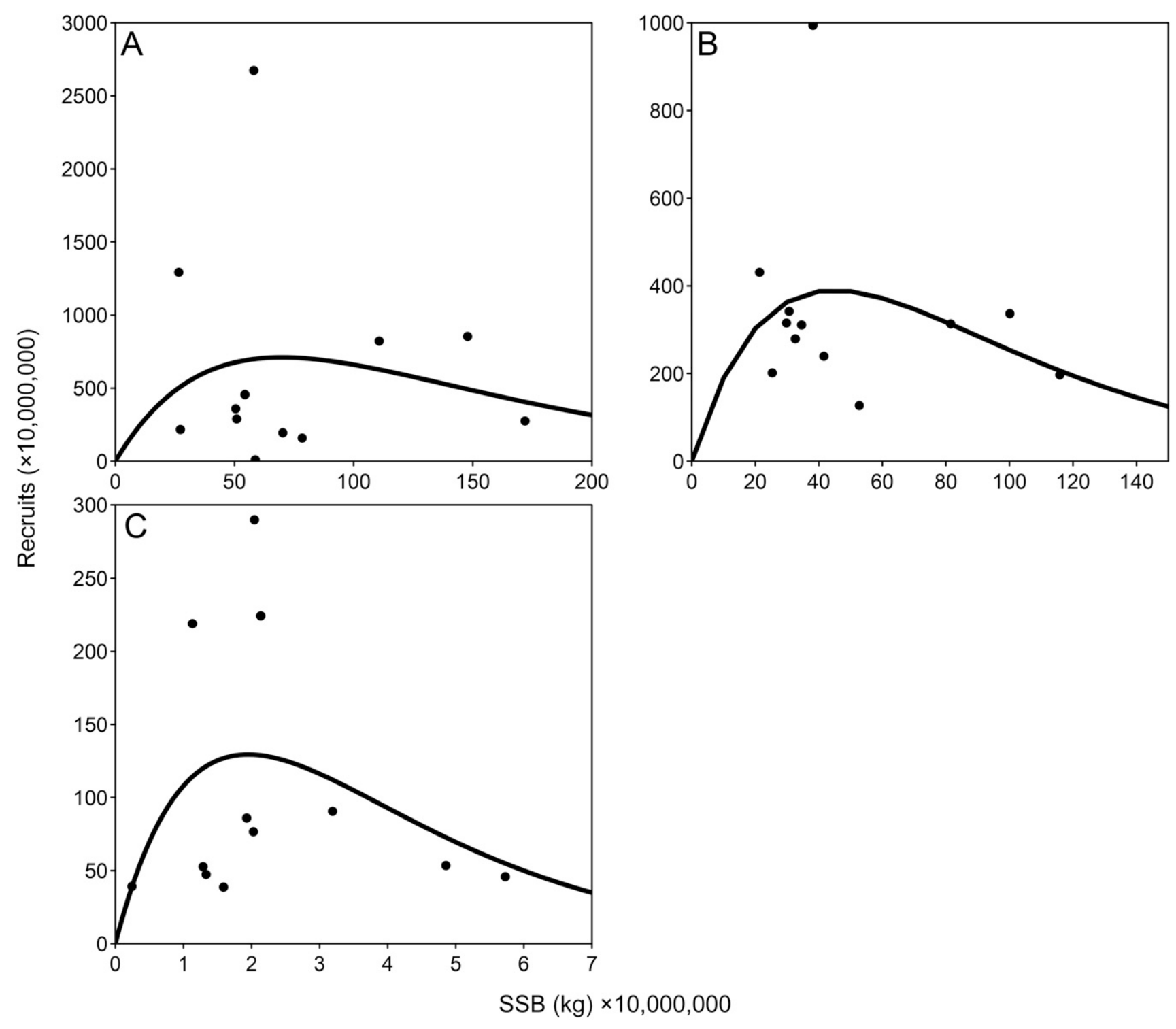

Figure 8. Spawning stock biomass versus recruits for the (A) DMV, (B) NJ, and (C) LI regions. Ricker curve fitted to each SSB (kg) versus recruit relationship.

These previous ruminations address mechanisms militating against a consistent relationship between SSB and recruitment as a function of the dynamics of the ecosystem, including hydrodynamics and agents of mortality. In possible contrast, the

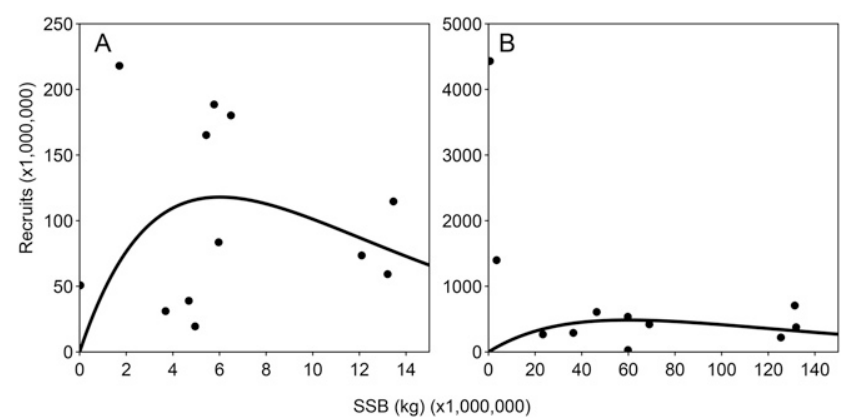

Figure 9. Spawning stock biomass versus recruits for the (A) SNE and (B) GBK regions. Ricker curve fitted to each $\mathrm{SSB}(\mathrm{kg})$ versus recruit relationship. surfclam stock has been judged to be near carrying capacity (NEFSC 2017) in that SSB is near the value anticipated to occur as a consequence of the balance between recruitment, growth, and natural mortality. This SSB level appears to be below that resulting in competition for food, as no evidence of such exists: constraints on growth in contrast appear to be a function of the influence of temperature on physiological processes that maintain clam maximum size near that which can be sustained by the individuals filtration rate and local food supply (Munroe et al. 2013, 2016). In this scenario, the variations in SSB and recruitment observed in the survey dataset may result from limitations in survey station density introducing biased outcomes, be they overestimates or underestimates, in each survey event. Obtaining unbiased survey SSB estimates for biomass dominants such as surfclams is inherently problematic (Powell \& Mann 2016, Powell et al. 2017). To what extent stochasticity-limiting detection and determinism-limiting existence of a relationship between SSB and recruitment contribute 


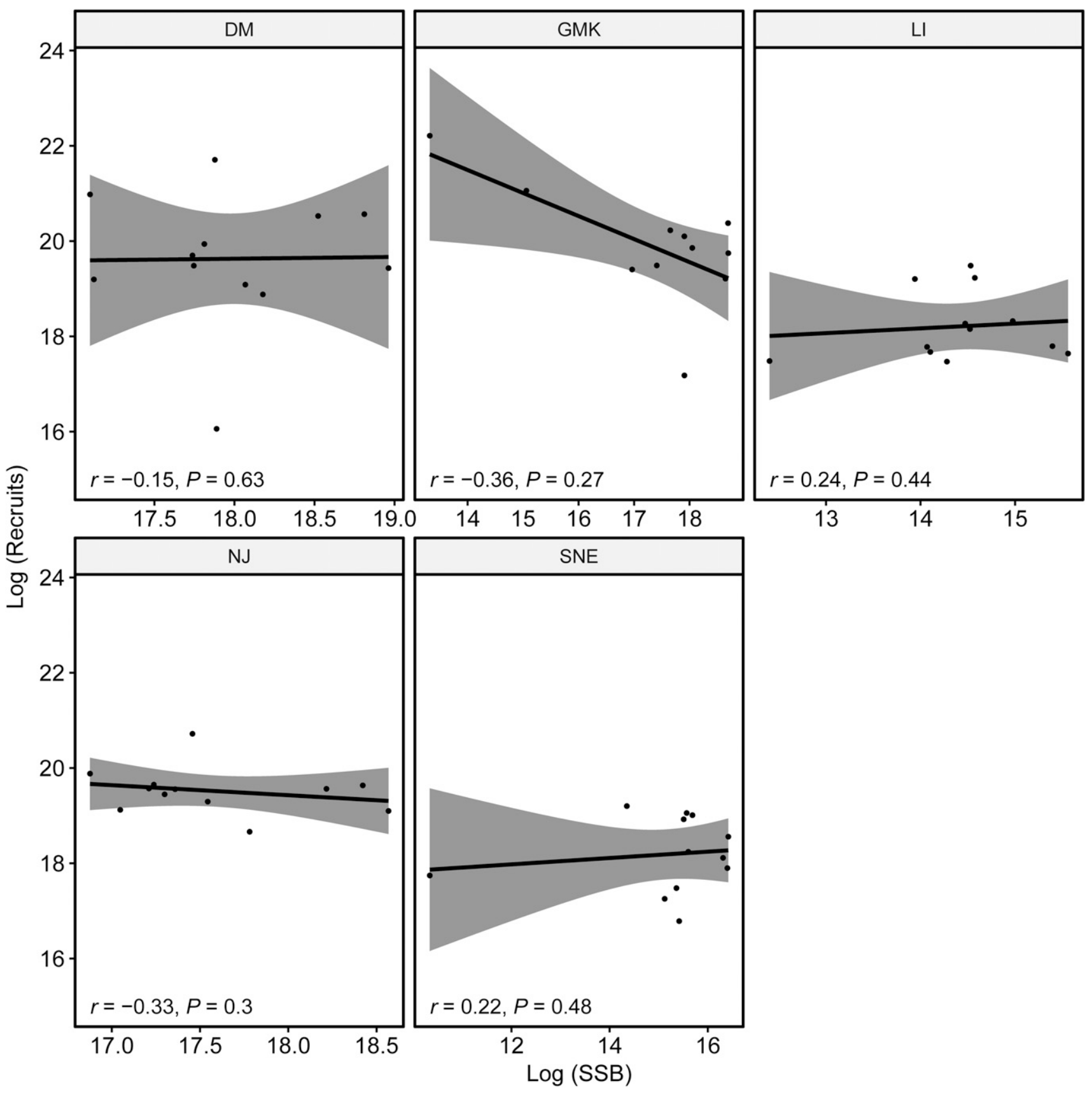

Figure 10. Spearman correlation testing possible relationships between the recruits and SSB (kg). The grey area represents the confidence intervals around the line.

to the failure to detect such a relationship in Atlantic surfclams cannot presently be ascertained.

Mean first passage times may not be adequate to describe the relationship between SSB and recruitment but they may be informative to the point of identifying certain unlikely transitions. The NJ region, for instance, has some transitions that are predicted to take 16 surveys (i.e., quadrant 4 to quadrant 2) before they occur and with surveys typically being 3 y apart, that is, a period of time that may not have occurred in the history of the surfclam fishery (Table 3). The mean first passage times for the DMV region on the other hand show no clear difference in transitions between states. The DMV region is different from the other regions in that it is primarily a sink for incoming larvae, while the other four regions are sources and sinks (Zhang et al. 2015). Thus, the DMV region draws recruits from a large upstream region and spawns larvae a large fraction of which are transported across the southern boundary where survival is highly unlikely. Both may enhance the chanciness of any particular recruitment event relative to the apparent SSB supporting it.

Any recruitment index derived from the current survey will be limited in use because of a bias in mortality of juveniles at and beyond the range boundaries and the inherent longterm and interannual variability in recruitment influenced by 
TABLE 4.

Stock-recruitment observations classified into quadrants based on division by the median recruits and median SSB.

\begin{tabular}{|c|c|c|c|c|}
\hline & S1 & S2 & S3 & S4 \\
\hline Region & Low stock/low recruitment & Low stock/high recruitment & High stock/high recruitment & High stock/low recruitment \\
\hline Delmarva & 2 & 4 & 2 & 4 \\
\hline New Jersey & 3 & 3 & 3 & 3 \\
\hline Long Island & 4 & 2 & 4 & 2 \\
\hline Southern New England & 4 & 2 & 4 & 2 \\
\hline Georges Bank & 4 & 2 & 3 & 2 \\
\hline
\end{tabular}

See Figure 2 for quadrant definitions.

changing hydrodynamics and post-settlement mortality. Interannual variability in recruitment is an important source of uncertainty (Rothschild et al. 2005), and warming bottom waters driving the surfclams into new habitat may be making this interaction between recruits and SSB more complex (Weinberg 2005). What is apparent from this study is that an easily resolved relationship between SSB and recruitment does not exist and that its absence is readily understood by the dynamics of a stock that exists over a broad region of the continental shelf and for which bet-hedging is an evolutionary adaptation to the uncertainty in recruitment success imposed by the environment of the continental shelf. What can then be inferred is that a recruitment index obtained from a survey is unlikely to routinely provide a useful forecast of future market-size abundance.

Of perhaps greater interest is the much larger effective areas for the recruits relative to the adult population. This phenomenon may be typical of bivalves, but studies that examine a large geographic region that would be needed to address this possibility are rare. This larger footprint for the recruits would appear at first glance to waste larvae, although a surfeit of larvae almost certainly exists. In reality, it continuously positions the species advantageously in response to unpredictable environmental changes in time and space. One consequence is the relatively rapid shift in range that has been observed in comparison with the species life span, a shift promoted by the extended effective area of the recruits. Whereas, the broader footprint of the recruits assures that a prediction of SSB from

TABLE 5.

Chi-square test on stock-recruitment observations classified into quadrants (Fig. 2, Table 4).

\begin{tabular}{lcc}
\hline \hline \multicolumn{1}{c}{ Chi-square } & \\
\hline \multicolumn{1}{c}{ Region } & DF & $\boldsymbol{P}$-value \\
\hline Delmarva & 3 & 0.721 \\
New Jersey & 3 & 1.000 \\
Long Island & 3 & 0.721 \\
Southern New England & 3 & 0.721 \\
Georges Bank & 3 & 0.484 \\
\hline
\end{tabular}

In no case was the distribution of observations between quadrants significantly different from the expectation that all observations are distributed uniformly between the four quadrants with no existing relationship between the stock and recruits. recruitment is unlikely to be achieved, the distribution of the recruits provides important information on the resiliency of the stock to climate change by identifying the potential of outlying regions to support future expansions of the stock.

TABLE 6.

Mean first passage times for DMV, NJ, LI, SNE and GB.

\begin{tabular}{|c|c|c|c|c|c|}
\hline \multirow[t]{7}{*}{ a. } & \multicolumn{5}{|l|}{ Delmarva } \\
\hline & Quadrant & 1 & 2 & 3 & 4 \\
\hline & \multicolumn{5}{|c|}{ Mean first passage time (survey) } \\
\hline & $1 \rightarrow$ & 5.50 & 3.00 & 5.33 & 2.67 \\
\hline & $2 \rightarrow$ & 4.33 & 3.67 & 4.17 & 3.33 \\
\hline & $3 \rightarrow$ & 5.67 & 5.00 & 5.50 & 1.00 \\
\hline & $4 \rightarrow$ & 4.67 & 4.00 & 4.50 & 2.75 \\
\hline \multirow[t]{7}{*}{ b. } & \multicolumn{5}{|l|}{ New Jersey } \\
\hline & Quadrant & 1 & 2 & 3 & 4 \\
\hline & \multicolumn{5}{|c|}{ Mean first passage time (survey) } \\
\hline & $1 \rightarrow$ & 5.50 & 9.00 & 8.00 & 4.00 \\
\hline & $2 \rightarrow$ & 2.00 & 5.50 & 10.00 & 6.00 \\
\hline & $3 \rightarrow$ & 8.50 & 17.50 & 3.67 & 1.50 \\
\hline & $4 \rightarrow$ & 7.00 & 16.00 & 4.00 & 2.75 \\
\hline \multirow[t]{7}{*}{ c. } & \multicolumn{5}{|c|}{ Long Island } \\
\hline & Quadrant & 1 & 2 & 3 & 4 \\
\hline & \multicolumn{5}{|c|}{ Mean first passage time (survey) } \\
\hline & $1 \rightarrow$ & 5.75 & 3.33 & 4.33 & 4.50 \\
\hline & $2 \rightarrow$ & 12.00 & 7.67 & 1.00 & 5.00 \\
\hline & $3 \rightarrow$ & 11.00 & 6.67 & 1.92 & 4.00 \\
\hline & $4 \rightarrow$ & 7.00 & 2.67 & 3.67 & 5.75 \\
\hline \multirow[t]{7}{*}{ d. } & \multicolumn{5}{|c|}{ Southern New England } \\
\hline & Quadrant & 1 & 2 & 3 & 4 \\
\hline & \multicolumn{5}{|c|}{ Mean first passage time (survey) } \\
\hline & $1 \rightarrow$ & 2.50 & 3.00 & 4.00 & 16.00 \\
\hline & $2 \rightarrow$ & 4.50 & 5.00 & 1.00 & 13.00 \\
\hline & $3 \rightarrow$ & 3.50 & 4.00 & 3.75 & 12.00 \\
\hline & $4 \rightarrow$ & 6.50 & 2.00 & 3.00 & 7.50 \\
\hline \multirow[t]{7}{*}{ e. } & \multicolumn{5}{|c|}{ Georges Bank } \\
\hline & Quadrant & 1 & 2 & 3 & 4 \\
\hline & \multicolumn{5}{|c|}{ Mean first passage time (survey) } \\
\hline & $1 \rightarrow$ & 4.67 & 5.00 & 14.00 & 1.00 \\
\hline & $2 \rightarrow$ & 4.33 & 3.50 & 9.00 & 3.00 \\
\hline & $3 \rightarrow$ & 4.67 & 5.00 & 14.00 & 1.00 \\
\hline & $4 \rightarrow$ & 3.67 & 4.00 & 13.00 & 2.33 \\
\hline
\end{tabular}

The time it takes for one quadrant to transition to another quadrant is given in terms of surveys, not years. Surveys are typically 3 y apart. A high transition time for remaining in a quadrant (i.e., 1-1) indicates a higher probability of a transition to another quadrant than remaining in original quadrant. Arrows indicate trajectories between quadrants. 


\section{ACKNOWLEDGMENTS}

This research was supported by the National Science Foundation Industry/University Cooperative Research Center SCeMFiS (Science Center for Marine Fisheries) through membership fees under the direction of the Industry Advisory Board (IAB). SCeMFiS administrative support is provided by NSF award \#1266057. Conclusions and opinions expressed herein are solely those of the authors. We thank the NMFS Northeast Fisheries Science Center for making available the datasets used in this study and acknowledge the many individuals of the NEFSC survey branch that participated in survey data collection over the last tricennial.

\section{LITERATURE CITED}

Adams, P. B. 1980. Life history patterns in marine fishes and their consequences for fisheries management. Fish. Bull. 78:1-12.

Adkins, S. C., J. D. Marsden \& J. C. Pirker. 2014. Variation in population structure and density of Austrovenus stutchburyi (Veneridae) from Canterbury, New Zealand. J. Shellfish Res. 33:343-354.

Ambrogio, O. V. \& J. A. Pechenik. 2009. Do sex-changing male snails use mate choice to get a jump on their "size advantage"? Mar. Biol. 156:2175-2180

Beukema, J. J. \& G. C. Cadée. 1996. Consequences of the sudden removal of nearly all mussels and cockles from the Dutch Wadden Sea Mar. Ecol. (Berl.) 17:279-289.

Beukema, J. J., R. Dekker, J. Drent \& J. van der Meer. 2017. Long-term changes in annual growth of bivalves in the Wadden Sea: influences of temperature, food, and abundance. Mar. Ecol. Prog. Ser. 573:143-156

Beukema, J. J., R. Dekker \& C. J. M. Philipport. 2010. Long-term variability in bivalve recruitment, mortality, and growth and their contribution to fluctuations in food stocks of shellfish-eating birds. Mar. Ecol. Prog. Ser. 414:117-130.

Brooks, E. N. 2013. Effects of variable reproductive potential on reference points for fisheries management. Fish. Res. 138:152-158.

Budgell, W. P. 2005. Numerical simulation of ice-ocean variability in the Barents Sea region. Ocean Dyn. 55:370-387.

Buroker, N. E. 1983. Sexuality with respect to shell length and group size in the Japanese oyster Crassostrea gigas. Malacologia 23 271-279.

Cargnelli, L. M., S. J. Griesbach, D. B. Packer \& E. Weissberger. 1999. Essential fish habitat source document: Atlantic surfclam, Spisula solidissima, life history and habitat characteristics. NOAA Tech. Mem. NMFS-NE 142:1-13.

Chaalali, A., G. Beaugrand, P. Boët \& B. Sautour. 2013. Climate-caused abrupt shifts in a European macrotidal estuary. Estuaries Coasts 36:1193-1205.

Chintala, M. M. \& J. P. Grassle. 2001. Comparison of recruitment frequency and growth of surfclams, Spisula solidissima (Dillwyn, 1817), in different inner-shelf habitats of New Jersey. J. Shellfish Res. 20:1177-1186.

Cushing, D. H. 1971. The independence of recruitment on parent stock in different groups of fishes. J. Cons. Cons. Int. Explor. Mer. 3 : 340-362.

DeAlteris, J. T. 2000. Stock and recruitment. In: Fisheries stock assessment user's manual, Atlantic States Marine Fisheries Commission, SR-69. pp. 124-137.

Dutertre, M., P. G. Beninger, L. Barillé, M. Papin \& J. Haure. 2010. Rising water temperatures, reproduction and recruitment of an invasive oyster, Crassostrea gigas, on the French Atlantic coast. Mar. Environ. Res. 69:1-9.

Fuentes-Santos, I. \& U. Labarta. 2015. Spatial patterns of larval settlement and early post-settlement survivorship of Mytilus galloprovincialis in a Galician Ría (NW Spain). Effect on recruitment success. Reg. Stud. Mar. Sci. 2:1-10.

Goldberg, R. 1989. Biology and culture of the surfclam. Dev. Aquacult. Fish. Sci. 19:263-276.

Goodwin, N. B., A. Grant, A. L. Perry, N. X. Dulvy \& J. D. Reynolds. 2006. Life history correlates of density-dependent recruitment in marine fishes. Can. J. Fish. Aquat. Sci. 63:494-509.
Grizzle, R. E. \& R. A. Lutz. 1989. A statistical model relating horizontal seston fluxes and bottom sediment characteristics to growth of Mercenaria mercenaria. Mar. Biol. 102:95-105.

Guillou, J. \& C. Tartu. 1994. Post-larval and juvenile mortality in a population of the edible cockle Cerastoderma edule (L.) from northern Brittany. Neth. J. Sea Res. 33:103-111.

Haidvogel, D. B., H. G. Arango, K. Hedstrom, A. Beckmann, P. Malanotte-Rizzoli \& A. F. Shchepetkin. 2000. Model evaluation experiments in the North Atlantic Basin: simulations in nonlinear terrain-following coordinates. Dyn. Atmos. Oceans 32:239-281.

Hancock, D. A. 1973. The relationship between stock and recruitment in exploited invertebrates. Rapp. P.-v. Réun. Int. Explor. Mer 164:113-131.

Harris, J. M., G. M. Branch, B. L. Elliott, B. Currie, A. H. Dye, C. D McQuaid, B. J. Tomalin \& C. Velasquez. 1998. Spatial and temporal variability in recruitment of intertidal mussels around the coast of southern Africa. S. Afr. J. Zool. 33:1-19.

Hilborn, R. \& C. J. Walters. 1992. Quantitative fisheries stock assessment: choice, dynamics, and uncertainty. Boston, MA: Springer. $538 \mathrm{pp}$.

Hofmann, E. E., E. N. Powell, J. M. Klinck, D. M. Munroe, R. Mann, D. B. Haidvogel, D. A. Narváez, X. Zhang \& K. M. Kuykendall. 2018. An overview of factors affecting distributions of the Atlantic surfclam (Spisula solidissima), a continental shelf biomass dominant, during a period of climate change. J. Shellfish Res. 37:821-831.

Honkoop, P. J. C., J. van der Meer, J. J. Beukema \& D. Kwast. 1998. Does temperature-influenced egg production predict the recruitment in the bivalve Macoma balthica? Mar. Ecol. Prog. Ser. 164:229-235.

Hornbach, D. J., T. E. Wissing \& A. J. Burky. 1981. Life-history characteristics of a stream population of the freshwater clam Sphaerium striatinum Larmarck (Bivalvia: Pisidiidae). Can. J. Zool. 60:249-260

Hunt, H. L., D. A. McLean \& L. S. Mullineaux. 2003. Post-settlement alteration of spatial patterns of soft shell clam (Mya arenaria) recruits. Estuaries 26:72-81.

Jackson, J. B. C., M. X. Kirby, W. H. Berger, K. A. Bjorndal, L. W. Botsford, B. J. Bourque, R. H. Bradbury, R. Cooke, J. Erlandson, J. A. Estes, T. P. Hughes, S. Kidwell, C. B. Lange, H. S. Lenihan, J. M. Pandolfi, C. H. Peterson, R. S. Steneck, M. J. Tegner \& R. R Warner. 2001. Historical overfishing and the recent collapse of coastal ecosystems. Science 293:629-637.

Jones, D. S., I. Thompson \& W. G. Ambrose. 1978. Age and growth rate determinations for the Atlantic surfclam Spisula solidissima (Bivalvia: Mactracea), based on internal growth lines in shell crosssections. Mar. Biol. 47:63-70.

Kim, Y. \& E. N. Powell. 2004. Surfclam histopathology survey along the Delmarva mortality line. J. Shellfish Res. 23:429-441.

Knights, A. M. 2012. Spatial variation in body size and reproductive condition of subtidal mussels: considerations for sustainable management. Fish. Res. 113:45-54.

Kraeuter, J., S. Buckner \& E. N. Powell. 2005. A note on a spawner-recruit relationship for a heavily exploited bivalve: the case of northern quahog (hard clams), Mercenaria mercenaria in the Great South Bay New York. J. Shellfish Res. 24:1043-1052.

Kraeuter, J. N., J. M. Klinck, E. N. Powell, E. E. Hofmann, S. C. Buckner, R. E. Grizzle \& V. M. Bricelj. 2008. Effects of the fishery 
on the northern quahog (= hard clam, Mercenaria mercenaria L.) population in Great South Bay, New York: a modeling study. J. Shellfish Res. 27:653-666.

Kuykendall, K. M., E. N. Powell, J. M. Klinck, P. T. Moreno \& R. T. Leaf. 2017. Management strategy evaluation for the Atlantic surfclam (Spisula solidissima) using a spatially explicit, vessel-based fisheries model. Fish. Bull. 115:300-325.

Lovich, J. E., J. R. Ennen, C. B. Yackulic, K. Meyer-Wilkins, M. Agha, C. Loughran, C. Bjurlin, M. Austin \& S. Madrak. 2015. Not putting all their eggs in one basket: bet-hedging despite extraordinary annual reproductive output of desert tortoises. Biol. J. Linn. Soc. Lond. 115:399-410.

Lucey, S. M. \& J. A. Nye. 2010. Shifting species assemblages in the northeast US continental shelf large marine ecosystem. Mar. Ecol. Prog. Ser. 415:23-33.

Ma, H., J. P. Grassle \& J. M. Rosario. 2006. Initial recruitment and growth of surfclams (Spisula solidissima Dillwyn) on the inner continental shelf of New Jersey. J. Shellfish Res. 25:481-489.

MacKenzie, C. L., Jr., D. J. Radosh \& R. N. Reid. 1985. Densities, growth, and mortalities of juveniles of the surf clam (Spisula solidissima) (Dillwyn) in the New York Bight. J. Shellfish Res. 5:81-84.

Mangel, M., A. D. MacCall, J. Brodziak, E. J. Dick, R. E. Forrest, R. Pourzand \& S. Ralston. 2013. A perspective on steepness, reference points, and stock assessment. Can. J. Fish. Aquat. Sci. 70:930-940.

McGarvey, R., F. M. Serchuk \& I. A. McLaren. 1993. Spatial and parent-age analysis of stock-recruitment in the Georges Bank sea scallop (Placopecten magellanicus) population. Can. J. Fish. Aquat. Sci. 50:564-574.

Morse, B. L. \& H. L. Hunt. 2013. Impact of settlement and early postsettlement events on the spatial distribution of juvenile Mya arenaria on an intertidal shore. J. Exp. Mar. Biol. Ecol. 448:57-65.

Munroe, D. M., D. A. Narvàez, D. Hennen, L. Jacobson, R. Mann, E. E. Hofmann, E. N. Powell \& J. M. Klinck. 2016. Fishing and bottom water temperature as drivers of change in maximum shell length in Atlantic surfclams (Spisula solidissima). Estuar. Coast. Shelf Sci. 170:112-122.

Munroe, D. M., E. N. Powell, R. Mann, J. M. Klinck \& E. E. Hofmann. 2013. Underestimation of primary productivity on continental shelves: evidence from maximum size of extant surfclam (Spisula solidissima) populations. Fish. Oceanogr. 22:220-233.

Myers, R. A., N. J. Barrowman, J. M. Hoenig \& Z. Qu. 1996. The collapse of cod in eastern Canada: the evidence from tagging data. ICES J. Mar. Sci. 53:629-640.

Narváez, D. A., D. M. Munroe, E. E. Hofmann, J. M. Klinck, E. N. Powell, R. Mann \& E. Curchitser. 2015. Long-term dynamics in Atlantic surfclam (Spisula solidissima) populations: the role of bottom water temperature. J. Mar. Syst. 141:136-148.

Northeast Fisheries Science Center (NEFSC). 2007. 44th Northeast Regional Stock Assessment Workshop (44th SAW) assessment report. United States Department of Commerce. NEFSC Ref. Doc. 07-10, 661 pp. Woods Hole, MA, January 2007.

Northeast Fisheries Science Center (NEFSC). 2013. 56th Northeast Regional Stock Assessment Workshop (56th SAW) assessment report. United States Department of Commerce. NEFSC Ref. Doc. 13-04, 491 pp. Woods Hole, MA, January 2013.

Northeast Fisheries Science Center (NEFSC). 2017. 61st Northeast Regional Stock Assessment Workshop (61st SAW) assessment report. United States Department of Commerce. NEFSC Ref. Doc. 17-05, 471 pp. Woods Hole, MA, January 2017.

Ólafsson, E. B., C. H. Peterson \& W. G. Ambrose. 1994. Does recruitment limitation structure populations and communities of macro-invertebrates in marine soft sediments: the relative significance of pre- and post-settlement processes. Oceanogr. Mar. Biol. Annu. Rev. 32:65-109.

Olofsson, H., J. Ripa \& N. Jonzén. 2009. Bet-hedging as an evolutionary game: the trade-off between egg size and number. Proc. R. Soc. Lond. B Biol. Sci. 276:2963-2969.
Perretti, C. T., M. J. Fogartry, K. D. Friedland, J. A. Hare, S. M. Lucey, R. S. McBride, T. J. Miller, R. E. Morse, L. O’Brien, J. J. Pereira, L. A. Smith \& M. J. Wuenschel. 2017. Regime shifts in fish recruitment on the northeast US continental shelf. Mar. Ecol. Prog. Ser. 574:1-11.

Peterson, C. H. 2002. Recruitment overfishing in a bivalve mollusc fishery: hard clams (Mercenaria mercenaria) in North Carolina. Can. J. Fish. Aquat. Sci. 59:96-104.

Peterson, C. H. \& H. C. Summerson. 1992. Basin-scale coherences of population dynamics of an exploited marine invertebrate, the bay scallop: implications of recruitment limitation. Mar. Ecol. Prog. Ser. 90:257-272.

Pianka, E. R. 1970. On r- and k-selection. Am. Nat. 104:592-597.

Powell, E. N. 2017. What is going on with Perkinsus marinus in the Gulf of Mexico? Estuaries Coasts 40:105-120.

Powell, E. N., K. A. Ashton-Alcox, J. N. Kraeuter, S. E. Ford \& D. Bushek. 2008. Long-term trends in oyster population dynamics in Delaware Bay: regime shifts and response to disease. J. Shellfish Res. 27:729-755.

Powell, E. N., H. Cummins, R. J. Stanton, Jr. \& G. Staff. 1984. Estimation of the size of molluscan larval settlement using the death assemblage. Estuar. Coast. Shelf Sci. 18:367-384.

Powell, E. N., E. E. Hofmann \& J. M. Klinck. 2018. Oysters, sustainability, management models, and the world of reference points. J. Shellfish Res. 37:833-849.

Powell, E. N., J. M. Klinck, K. A. Ashton-Alcox \& J. N. Kraeuter. 2009. Multiple stable reference points in oyster populations: biological relationships for the eastern oyster (Crassostrea virginica) in Delaware Bay. Fish. Bull. 107:109-132.

Powell, E. N., J. M. Klinck, D. M. Munroe, E. E. Hofmann, P. Moreno \& R. Mann. 2015. The value of captain's behavioral choices in the success of the surfclam (Spisula solidissima) fishery on the U.S. Mid-Atlantic coast: a model evaluation. J. Northwest Atl. Fish. Sci. 47:1-27.

Powell, E. N. \& R. Mann. 2016. How well do we know the infaunal biomass of the continental shelf? Cont. Shelf Res. 115:27-32.

Powell, E. N., R. Mann, K. A. Ashton-Alcox, K. M. Kuykendall \& M. C. Long. 2017. Can we estimate molluscan abundance and biomass on the continental shelf? Estuar. Coast. Shelf Sci. 198:213-224.

Quijón, P. A., J. P. Grassle \& J. M. Rosario. 2007. Naticid snail predation on early post-settlement surfclams (Spisula solidissima) on the inner continental shelf of New Jersey. Mar. Biol. 150:873882.

Redner, S. 2001. A guide to first-passage processes. Cambridge, UK: Cambridge University Press. 328 pp.

Rijnsdorp, A. D., M. A. Peck, G. H. Engelhard, C. Möllmann \& J. K. Pinnegar. 2009. Resolving the effect of climate change on fish populations. ICES J. Mar. Sci. 66:1570-1583.

Rothschild, B. J., C. Chen \& R. G. Lough. 2005. Managing fish stock under climate uncertainty. ICES J. Mar. Sci. 62:1531-1541.

Rothschild, B. J. \& A. J. Mullen. 1985. The information content of the stock-and-recruitment data and its non-parametric classification. ICES J. Mar. Sci. 42:116-124.

Sha, J., Y.-H. Jo, X.-H. Yan \& W. T. Liu. 2015. The modulation of the seasonal cross-shelf sea level variation by the cold pool in the Middle Atlantic Bight. J. Geophys. Res. Oceans 120:7182-7194.

Shephard, S., B. Beukers-Stewart, J. G. Hiddink, A. R. Brand \& M. J. Kaiser. 2010. Strengthening recruitment of exploited scallops Pecten maximus with ocean warming. Mar. Biol. 157:91-97.

Shepherd, S. A., J. R. Turrubiates-Morales \& K. Hall. 1998. Decline of the abalone fishery at La Natividad, Mexico: overfishing or climate change? J. Shellfish Res. 17:839-846.

Stearns, S. 1976. Life-history tactics: a review of the ideas. Q. Rev. Biol. 51:3-47.

Tettelbach, S. T., J. R. Europe, C. R. H. Tettelbach, J. Havelin, B. S. Rodgers, B. T. Furman \& M. Velasquez. 2017. Hard clam walking. 
Active horizontal locomotion of adult Mercenaria mercenaria at the sediment surface and behavioral suppression after extensive sampling. PLoS One 12:1-22.

Tettelbach, S. T., B. J. Peterson, J. M. Carroll, S. W. T. Hughes, D. M. Bonal, A. J. Weinstock, J. R. Europe, B. T. Furman \& C. F. Smith. 2013. Priming the larval pump: resurgence of bay scallop recruitment following initiation of intensive restoration efforts. Mar. Ecol. Prog. Ser. 478:153-172.

Timbs, J. R., E. N. Powell \& R. Mann. (In Review). Changes in the spatial distribution and anatomy of a range shift for Atlantic surfclams, Spisula solidissima, in the Mid-Atlantic Bight and on Georges Bank. Mar. Ecol. Prog. Ser.

Thorson, J. T., M. L. Pinsky \& E. J. Ward. 2016. Model-based inference for estimating shifts in species distribution, area occupied, and center of gravity. Methods Ecol. Evol. 7:990-1008.

van der Meer, J., J. J. Beukema \& R. Dekker. 2003. Large spatial variability in life time egg production in an intertidal Baltic tellin (Macoma balthica) populations. Helgol. Mar. Sci 56:274-278.

Warner, J. C., W. R. Geyer \& J. A. Lerczak. 2005. Numerical modeling of an estuary: a comprehensive skill assessment. J. Geophys. Res. Oceans 110:1-13.
Weinberg, J. R. 1999. Age-structure, recruitment, and adult mortality in populations of the Atlantic surfclam, Spisula solidissima, from 1978 to 1997. Mar. Biol. 134:113-125.

Weinberg, J. R. 2005. Bathymetric shift in the distribution of Atlantic surfclams: response to warmer ocean temperature. ICES J. Mar. Sci. 62:1444-1453.

Weinberg, J. R., E. N. Powell, C. Pickett, V. A. Nordahl, Jr. \& L. D. Jacobson. 2005. Results from the 2004 cooperative survey of Atlantic surfclams. United States Department of Commerce. NEFSC Ref. Doc. 05-01, 1-41. Woods Hole, MA.

Wells, H. W. \& I. E. Gray. 1960. The seasonal occurrences of Mytilus edulis on the Carolina coast as a result of transport around Cape Hatteras. Biol. Bull. 119:550-559.

Zhang, X., D. Haidvogel, D. Munroe, E. N. Powell, J. Klinck, R. Mann \& F. S. Castruccio. 2015. Modeling larval connectivity of the Atlantic surfclams within the Middle Atlantic Bight: model development, larval dispersal and metapopulation connectivity. Estuar. Coast. Shelf Sci. 153:38-53.

Zhang, X., D. Munroe, D. Haidvogel \& E. N. Powell. 2016. Atlantic surfclams connectivity within the Middle Atlantic Bight: mechanisms underlying variation in larval transport and settlement. Estuar. Coast. Shelf Sci. 173:65-78. 